\title{
Blanco White: un militante contra el absolutismo. Del liberalismo a la cuestión colonial
}

I. La figura de Blanco White

Si bien el regreso de Fernando VII al trono de España, en 1814, venía a confirmar la escasa carga revolucionaria y modernizadora de la Guerra de la Independencia, no es posible

José María Blanco White es uno de los personajes más atractivos de la historia contemporánea de España en sus comienzos, y uno de los más injustamente denostados.

Pero a pesar de que la obra y el pensamiento de Blanco White son hoy todavía bastante desconocidos, este controvertido y poco ortodoxo liberal es un exponente fundamental de la crisis de conciencia más importante que ha conocido España en toda su historia: la crisis del Antiguo Régimen, con la quiebra de la llustración y el surgimiento de la nueva época liberal en los años de la Guerra de la Independencia. Su exilio en Inglaterra (I8I0-184I) le permitió

no solo tratar estrechamente a algunos de los grandes pensadores británicos, sino descubrir América. Allí se dará cuenta de que hay una parte de España que puede y debe librarse del yugo de la tiranía y del mal gobierno.

Palabras clave: Blanco White, semanario patriótico, el español, constitucionalismo 1812, Jeremy Bentham, ilustración hispanoamericana.

- Investigadora permanente del Grupo de Investigación Derechos Fundamentales, Andalucía y U.E (SEJ-173), de la Universidad de Jaén ajara6@ugr.es dudar que, como concluyera ya hace años Tuñón de Lara (1973: 9), "la conmoción nacional del período 1808-1813 había quebrantado irremediablemente la solidez del antiguo régimen. Había permitido cierta difusión de las ideas nuevas, un agrupamiento de los sectores sociales más progresistas". La convulsión intelectual e ideológica subyacente al fenómeno bélico es, de acuerdo con la perspectiva histórica, la que permitió el nacimiento de un nuevo sujeto público colectivo sobre el que, al fin y a la postre, habría de recaer la tarea modernizadora y transformadora del siglo XIX español.

La 'nueva opinión pública', nacida de esa sacudida intelectual y deudora de las recién estrenadas libertades de imprenta y opinión, tiene en José María Blanco y Crespo, Blanco White (Sevilla 1775Liverpool 1841), liberal y comba-

Espiral, Estudios sobre Estado y Sociedad

Vol. XxI No. 61 ป Septiembre / Diciembre de 2014 
tiente contra el absolutismo, uno de sus más destacados agitadores y, desde luego, un valioso exponente de nuestro mejor periodismo político. El Semanario Patriótico, una publicación de cronología irregular e itinerante (Madrid, Sevilla, Cádiz) da cuenta, sobre todo en su etapa sevillana (1809), del activismo de Blanco White para lograr "unas instituciones políticas acordes con unos objetivos revolucionarios que los liberales ya tenían claramente definidos en 1808" (Rico Linage, 2005: XV).

El Dictamen sobre el modo de reunir las Cortes en España, encargo de la Universidad de Sevilla redactado por Blanco White, reitera la posición doctrinal y política de Blanco, si bien responde a la gravedad del momento y transpira una cierta desconfianza sobre la previsible evolución de los acontecimientos. En todo caso, como afirma la profesora Rico Linage, todavía "en opinión de Blanco, las Cortes serán fuente de felicidad para los españoles venideros, de una felicidad que los liberales relacionan con la ausencia de despotismo y que, unos años después y en estrecha sintonía con esta misma doctrina política, nombrará expresamente el art. 13 de la Constitución de 1812 como finalidad del gobierno de la nación" (Rico Linage, 2005: CXIV).

Más adelante Blanco White, auto-expatriado en Inglaterra, continuará mirando a España y sus problemas principalmente a través de $E l E$ spañol ${ }^{1}$ y sus Letters from Spain, ${ }^{2}$ obra esta que los españoles no leerían en su idioma hasta 1972, como Cartas de España. Estas Cartas, que son en rigor un libro de viajes, constituyen las crónicas más sensibles de la miseria moral, intelectual y política de los últimos

I. Periódico que publicó en Londres y se editó mensualmente entre 1810 y 1813 y bimestralmente su último año de existencia, $|8| 4$, el mismo año en el que Fernando VII acabó con las Cortes doceañistas y las libertades que estas propugnaron, entre ellas el primer decreto de libertad de imprenta de la historia de España.

2. Joseph Blanco White, Letters from Spain. By Leucadio Doblado, Henry Colburn, Londres, 1825. 
Blanco White: un militante contra el absolutismo. Del liberalismo a la cuestión colonial

años del Imperio español. Al mismo tiempo presentan un testimonio intelectual privilegiado del fracaso de los ideales ilustrados europeos en nuestro país y el desengaño que este fracaso supuso (Subirats, 2005: 11).

Desde los días de Sevilla, donde Blanco entró en contacto personal con Lord Holland, que habría de convertirse en su principal valedor en Londres, Blanco participa de la idea de la gran cuestión política -el gran affaire del que Jovellanos hablaba al propio Holland-que no es otro que la reunión de las Cortes y la aprobación de un código de leyes fundamentales para la nación española (Moreno Alonso, 2011: 516).

El 4 de mayo de 1809 aparece el primer número de la conocida como 'etapa sevillana' del Semanario, cuya parte política redactó White personalmente, por encargo de su fundador Manuel José Quintana. Apenas unos días después, el 22 del mismo mes, se promulgaba el decreto de convocatoria a Cortes, lo que no pasaría de ser una simple coincidencia cronológica si no se advierte que en el núcleo básico del ideario político del Semanario Patriótico figuraba, desde su nacimiento, el objetivo de alcanzar nuevas leyes que, sustituyendo al despotismo, garantizasen los derechos de los españoles y protegiesen su libertad civil, para cuyo logro se hacía necesaria la convocatoria de unas Cortes en las que imperase el protagonismo de la representación nacional. Las Cortes se constituyeron el 24 de septiembre de 1810, cuando Blanco White ya había abandonado España. $\mathrm{Su}$ permanencia en la partitura del pensamiento liberal español, su presencia ideológico-política en aquellas Cortes y su influencia intelectual en la Constitución nacida en Cádiz en 1812 no admiten, sin embargo, dudas razonables (Moreno Alonso, 1989, 1997 y 2011).

Solo con una autoridad limitada por el imperio de la ley, sujeta a leyes, puede lograrse la felicidad pública. La ley constituida como fuente exclusiva del derecho, frente al derecho histórico y el privilegio; la independencia, la 
libertad, la Constitución y las leyes no pueden ser bienes otorgados, sino fruto del consentimiento deliberado y espontáneo del pueblo a cuya felicidad se destinan; la Constitución concebida como mecanismo de freno al egoísmo político y la arbitrariedad del poder; las Cortes son únicamente el mecanismo instrumental para alcanzarla; la Monarquía, sometida a leyes, como modelo compatible con la libertad política; la compatibilidad entre libertad e igualdad a través del principio de igualdad jurídica; la importancia decisiva de activar la voluntad general; la constante invocación y el respeto al 'voto de la nación'; el concepto político de felicidad vinculado a la soberanía nacional y la división de poderes o la naturaleza del mandato representativo... He aquí una serie de conceptos e ideas programáticas que anticipaban, desde el liberalismo y el iusnaturalismo racionalista ilustrado, una parte importante del texto constitucional de Cádiz.

\section{El pensamiento político de White}

La influencia de las ideas de la Revolución francesa en el pensamiento liberal de Blanco White está ampliamente documentada y generalmente admitida, pero no han de minimizarse, ni mucho menos descartarse, sus influencias inglesas. Albert Derozier, un acreditado investigador del liberalismo español, constató el manifiesto "entusiasmo por todo lo inglés" de White, cuya lucidez "hace de él -afirma el autor francés- un pensador al margen del liberalismo tradicional y que le da una dimensión que sólo hoy estamos en condiciones de apreciar" (Derozier, 1975: 248-253). No podemos más que añadir que tal vez ni siquiera hoy estemos en condiciones de valorar seriamente el alcance del pensamiento de White, a quien Eduardo Subirats (2005: 10) describe sucintamente como "el único intelectual filosóficamente consistente del siglo XIX español”. 
Blanco White: un militante contra el absolutismo. Del liberalismo a la cuestión colonial

Está también ampliamente documentado el influjo de las ideas de Bentham en España, especialmente su reconocimiento e influencia en el Trienio Constitucional (1820-1823), que ha permitido a algún especialista afirmar que "Bentham fue el 'padre espiritual' de muchos de los creadores de la España moderna, a quienes ofrece, entre otras cosas, su pluralismo metodológico, su antidogmatismo y su filosofía de la utilidad" (Pendás García, 1991: 21).

Blanco White, en realidad, era un anglófilo cuya anglofilia le había llevado a una virulenta francofobia, aunque quizá no sea ocioso advertir que su anglofilia consistía en una admiración muy grande por la organización política inglesa (por su Estado), pero no tanto por su sociedad (Varela Suanzes, 1993: 106).

Previamente White se había ocupado de la teología con tanto apasionamiento como se ocupó posteriormente de la política. No puede extrañar: a los catorce años inició sus estudios religiosos y en 1796 recibió el título de bachiller en teología. Fue miembro de la Academia de Letras Humanas, donde compartía inquietudes con los sevillanos más destacados de su tiempo. En 1799 fue ordenado sacerdote y dos años después fue nombrado capellán magistral de la Real Capilla de San Fernando. En 1802 tuvo la primera de las crisis religiosas que lo acompañarían toda su vida. En 1805, alegando motivos de salud, obtuvo licencia de las autoridades eclesiásticas y fue a Madrid. Dos años más tarde, fue nombrado miembro de la comisión asesora del Instituto Pestalozziano, institución educativa moderna que chocaba frontalmente con el integrismo tradicionalista y el control eclesiástico de la educación (Breña, 2002: 1). En Cartas de España afirma, por ejemplo:

[P]ocas son las ventajas que un joven puede sacar de los estudios universitarios en España. Esperar que exista un plan racional de estudios en un país en que la Inquisición está constantemente al acecho para mantener 
el entendimiento humano dentro de los límites que la Iglesia romana, con su ejército de teólogos [...], sería manifestar un desconocimiento total de las características de nuestra religión. Gracias a la unión que hay entre nuestra Iglesia y nuestro Estado, los teólogos católicos han conseguido mantener la instrucción pública a su mismo nivel. Aun las ramas de la ciencia que parecen menos relacionadas con la religión, no pueden escapar de la férula de los teólogos, y el mismo espíritu que hizo a Galileo retractarse de rodillas de sus descubrimientos astronómicos, todavía obliga a nuestros profesores a enseñar el sistema de Copérnico como una hipótesis (Peset y Peset, 1974: 707).

White redactó por primera vez su autobiografía religiosa sin propósito de publicarla, "por esa íntima necesidad de justificación que siente todo converso" (Llorens, 1986: 23). Más tarde la incluyó en las Cartas de España, contribuyendo a destacar la importancia de la religión en la vida española, pero movido también por otras consideraciones. De un modo notable, casi tierno al describir las motivaciones de White, explica el profesor Vicente Llorens (1986: 24-25) estos motivos en su introducción a las Cartas en castellano:

Cualquiera podía preguntar: ¿Cómo ahora, al restaurarse la libertad política en España, que había acabado, entre otras cosas, con la Inquisición y los libros prohibidos, venía a trazarse un cuadro nacional velado aún por sombras inquisitoriales que ya no pertenecían sino al pasado? Para Blanco, sin embargo, aquel pasado seguía siendo presente, mientras persistiera en la Constitución española la anomalía de proclamar todas las libertades menos la religiosa. Su cuadro, pues, no era tan anacrónico; y los liberales mal podían vanagloriarse de haber renovado la vieja España, mientras siguieran manteniendo el conformismo religioso que en otro tiempo fue causa de sus sufrimientos personales. Aunque, los liberales, por otra parte, eran los mismos que años antes le acusaron y persiguieron, haciéndole difícil su vida en Inglaterra, y forzándole indirectamente a buscar seguridad, a su anglificación política y religiosa. Se trata de una confesión, mas no rousseauniana. "No poseo [...] el 
Blanco White: un militante contra el absolutismo. Del liberalismo a la cuestión colonial

cinismo intelectual que me permitiría, como a Rousseau, exponer mi corazón desnudo a la mirada de los demás. No tengo tampoco su odiosa y desgraciada propensión a expresarme con afectada franqueza ni su cautivadora elocuencia; $y$ como he de vencer no pequeñas resistencias por mi parte y el sentimiento del decoro para decidirme a escribir un relato que concierne a mi entendimiento y mi razón, tengo algún motivo para creer que lo emprendo impulsado por un sincero deseo de ser útil a los demás”.

Para Blanco, Inglaterra fue la tierra de la libertad y por esta razón pudo desarrollarse intelectualmente sin los impedimentos externos y las trabas tradicionalistas que le imponía la sociedad española. El pensamiento de Blanco fluyó sin grandes estorbos y la distancia, tanto como intensificaba sus recuerdos y nostalgias, dotó sus juicios de mayor lucidez y profundidad. Se trata de la lucidez de un desterrado que ama y se obsesiona por su país y a quien defraudan los acontecimientos, en especial, la imposibilidad de una reforma política que aproximara las instituciones españolas a las tan admiradas inglesas (Martínez de Pisón, 2005: 10). Puede decirse que en Blanco White se inaugura una forma desgarrada de ser español. España contemplada, evocada y pensada desde el destierro forja un tipo humano quizás no reconocible en otras latitudes, pero muy frecuente (Escamilla Castillo y Lázaro Paniagua, 2001: 322).

El exilio, adicionalmente, ofrece a White posibilidades de obtener documentos e información y pone a su alcance una perspectiva vital, cultural y política que España, sin duda, le hubiera negado, y cuya ausencia se pone de manifiesto en otros pensadores de la época. Los llamados ilustrados españoles carecieron de la crítica a la tiranía de las ideas:

Ni Feijoo, ni Cadalso, ni Jovellanos, ni Cabarrús ponen en cuestión los dogmas y los valores impuestos por la Inquisición. Incluso, el concepto mismo de llustración era excesivamente ambiguo [...]. En la Península 
Ibérica y en América Latina se divulgaron las llamadas ciencias útiles, se impusieron reformas institucionales que podemos llamar ilustradas en la medida en que respondían a una visión secular de productividad económica y racionalidad instrumental, y se defendió un ideal de progreso que, de un modo u otro, se parecía a los idearios de la filosofía de la historia de Condorcet o de Kant. Pero el concepto de llustración se mantuvo siempre en una penumbra intelectual, sin límites precisos que la distinguiesen de la metafísica escolástica o del dogmatismo católico, y de las atrasadas formas y valores sociales que amparaban (Martínez de Pisón 2005: 31).

Se hace necesario matizar estas afirmaciones, es cierto que Jovellanos llegó tarde al liberalismo, en el sentido político y constitucional de este término, sin que lo aceptase nunca plenamente, sin embargo, trató asimismo (como algunos diputados liberales de las Cortes de Cádiz, como Muñoz Torrero y Argüelles) de buscar la "vía media entre la España liberal y la España reaccionaria, entre la europeizante y la castiza" (Varela Suanzes, 1993: 115). Con todos los matices, es preciso reconocer que el intento conciliador de Blanco era mucho menos arcaizante y dieciochesco que el de Jovellanos y a la vez más prudente y perspicaz que el de los liberales doceañistas:

Mientras éstos se habían decantado por un modelo constitucional a todas luces demasiado avanzado para la realidad social española y que resultaría tan inoperante en la práctica como lo había resultado el de I79I, como se pondría de relieve sobre todo durante el trienio de 1820-1823, Blanco se inclina por un modelo más moderado y realista, aparentemente menos proclive a las profundas transformaciones de todo orden que España necesitaba [...], pero a la postre más eficaz y duradero. Eso sí, más eficaz y duradero siempre y cuando [...] Fernando VII, los grandes de España y el clero estuviesen dispuestos a aceptarlo honesta y sinceramente (Varela Suanzes, 1993: II5). 
Blanco White: un militante contra el absolutismo. Del liberalismo a la cuestión colonial

\section{I. Adhesión al pragmatismo inglés}

Durante los años de El Español (1810-1814) White está completamente concentrado en la política que quiere hacer llegar a los españoles de ambas orillas del Atlántico. En este marco, Inglaterra debía servir al gobierno de España como alternativa constitucional al modelo francés, dado que su influencia es, según su entender, nefasta, en las Cortes de Cádiz y en la Constitución de 1812 (Moreno Alonso, 2011: 516). En su crítica a este modelo se pone de manifiesto el influjo de diversos autores ingleses, poco o nada conocidos en España por aquel entonces, como Jeremy Bentham, que es el autor inglés más publicado y comentado en El Español (Dinwiddy, 1988: 565-73; Conway, 1988: 16-7, 34, 43, 73-5; Dinwiddy, 1975: 683-700).

En septiembre de 1810 aparece en este periódico un trabajo titulado "Modo de proceder en la Cámara de los Comunes de Inglaterra", traducido del inglés por White y que con más extensión había redactado "uno de los primeros jurisconsultos de Londres", que no era otro que Bentham. Se trataba de una especie de borrador de reglamento parlamentario que White confía sea tenido en cuenta por los miembros de las Cortes de Cádiz y que Mirabeau ya había recomendado, sin éxito, a la Asamblea francesa de 1789 (Varela Suanzes, 1993: 107).

En el número enero/febrero de 1814, Blanco White acoge, una vez más, la obra de Bentham, dando noticia de la Théorie des Peines et des Récompenses, publicada por Dumont en 1811. El texto expresa una concepción de la pena como instrumento universal de seguridad, y esa indicación, como se verá, puede haber ejercido una significativa influencia sobre el positivismo jurídico de Bolívar y sobre las instituciones morales. La presencia de Bentham en las páginas de El Español se concluye finalmente en 1814, cuando Blanco White publica la traducción de la sección Des Colonies de la Théorie des Peines et des Récompenses. La revista se 
convierte así en vehículo del anticolonialismo benthamiano en los territorios de ultramar.

Aunque Blanco tuvo contacto, a menudo estrecho, con grandes pensadores británicos de la época, como Malthus, Whately o John Stuart Mill, el caso de Jeremy Bentham es especial, porque su interés más profundo por la causa española llegó ya en el Trienio Liberal. En 1808 buscó la ayuda de Lord Holland, quien por esas fechas ya se encontraba en España, para que intercediese ante Jovellanos para conseguir los permisos necesarios para viajar a México. El plan quedó abandonado finalmente antes de que obtuviese una respuesta final, pero el tema español no desapareció. Autores de relieve en este campo sostienen que las colonias españolas son utilizadas por Bentham como trampolín para llegar a lo que verdaderamente le inquieta con respecto a España: la estabilidad del régimen liberal, que ya había sido derrotado una vez (Schwartz y Rodríguez Braun, 1983). Esta es la razón que explicaría, según estos autores, por qué se ocupa Bentham de las colonias españolas cuando parecía que muchas de ellas se estaban independizando: porque no estaba escribiendo sobre colonias, sino sobre la situación de España. Al mismo tiempo, se estaba carteando con líderes iberoamericanos, ofreciéndose como legislador. En la inconclusa obra Libraos de Ultramar ofrece también sus servicios, y se declara exento de toda corruptibilidad.

No hay duda de que las colonias podrían desaparecer, pero la Constitución de 1812 no, y White veía en ella -como Bentham-múltiples defectos. La mayor parte de los males, desde lo breve del período de sesiones de las Cortes hasta la dificultad para la reforma del texto constitucional y el incontrolable poder de patronazgo del rey, resultan independientes en gran medida de Ultramar: seguirían existiendo aunque las colonias se desvaneciesen. Parece como si Bentham hubiese empezado por la cuestión colonial y al percibir la importancia del problema constitucional hubiese 
Blanco White: un militante contra el absolutismo.

Del liberalismo a la cuestión colonial

desviado su atención hacia este, del cual había mucho que decir. Había descubierto Bentham que las colonias y la Constitución eran incompatibles: "Ello me ha conducido a la necesidad de revelar los defectos que tiene la Constitución, defectos tan graves que, de no ser remediados, todo acabará en una ruina completa, o el despotismo tomará el lugar de la libertad" (Rodríguez Braun, 1985: 502 y ss).

\section{Blanco: la defensa del liberalismo y la independencia} colonial americana

Si algo ocupó con preferencia la mente de Blanco White y los contenidos de $E l$ Español durante el verano de 1810 fue la situación generada en América entre abril y mayo de ese año con la creación de las juntas de Caracas y Buenos Aires. $\mathrm{Al}$ cerrar el primer tomo, con los seis primeros números, Blanco se permitió hablar de sí mismo, principalmente para defenderse. Ya en aquellos primeros momentos su periódico había sido acusado en Cádiz de promover la separación de las provincias americanas, de fomentar el desánimo entre los patriotas españoles (Garnica, Portillo y Vallejo, 2009: XXV) y de estar vendido al oro del gobierno inglés. Sin embargo, el hecho de ver con simpatía que aquellas provincias sacudieran el yugo de la tiranía, lanzándose por derroteros de libertad y de progreso, habría de causarle a White mayores heridas que estas iniciales acusaciones. Los periódicos españoles no solo vilipendiaban la actitud de Blanco, sino que le colmaban de vituperios e insultos, incluso aquellos cuyos redactores él había considerado amigos (Méndez Bejarano, 2009: 91-2). Se insultó a Blanco también en las Cortes de Cádiz por juzgarle redactor del escrito del Duque de Alburquerque; se prohibió la circulación de El Español en la península y en las colonias y se le declaró 'reo de lesa nación'. 
Pero el pensamiento de Blanco y su localización en Londres fue, como se ha mencionado, no solo una fuente de agravios. El exilio en la capital inglesa fue la gran ventaja que proporcionó a Blanco una perspectiva más amplia de los acontecimientos. Londres fue el principal centro de reunión y el foco propagandístico europeo de muchos patriotas hispanoamericanos durante el proceso emancipador. La lucidez de Blanco y la información de la que él disponía hicieron de El Español un punto de referencia obligado para los patriotas americanos. Su difusión por toda Hispanoamérica está plenamente documentada (Breña, 2002: 3).

Ejemplos de esta difusión son la conocida referencia de Bolívar a El Español en su "Carta de Jamaica" y la frecuencia con que el periódico de Blanco aparece toda vez que se revisan textos americanos escritos durante los cuatro años de existencia de El Español (Breña, 2002: 3). Su influencia, sin embargo, fue más allá de esos cuatro años. En el caso de México, por ejemplo, se sabe que legisladores que participaron en la redacción de la Constitución de 1824 revisaron y utilizaron El Español (Ferrer y Luna, 1996: 21).

El 25 de octubre de 1810, Bentham escribió a Blanco White a propósito de su conocimiento de que las Cortes se disponían a redactar una ley dedicada a la libertad de prensa, enviándole un borrador redactado "a petición de un amigo común" (Conway, 1988: 74-5). A través de las páginas de El Español de enero de 1811 la propuesta de Bentham llegó no solo a España, sino también a la revista La Bagatela de Bogotá, dirigida por el futuro presidente de Cundinamarca, Antonio Nariño, y, por último, a la Gaceta de Caracas, guiada por Vicente Azuero (Rudán, 2010: 19 y ss). Esta amplia circulación de las ideas impone considerar el papel jugado por El Español como vehículo de las ideas liberales en el mundo latinoamericano (Murphy, 1989).

White publica también la Noticia de una obra inédita intitulada Tactique des Assemblées Politiques, que el libe- 
Blanco White: un militante contra el absolutismo. Del liberalismo a la cuestión colonial

ral español pudo consultar gracias a la cortesía de Etienne Dumont, el traductor al francés de las obras de Bentham, así como una elogiosa recensión del libro Théorie des Peines et des Recompenses (Varela Suanzes, 1993: 107). El primer texto está ilustrado en detalle en el número de octubre de 1810, con el objeto de influir en la organización de las Cortes, aunque el efecto más significativo de su publicación tiene lugar en Colombia durante el Congreso de Cúcuta, convocado en 1821 para ratificar la Constitución venezolana de 1819. En esa circunstancia adversa, en efecto, Antonio Nariño propone adoptar como reglamento parlamentario las Tactiques de Bentham, citando íntegramente los fragmentos de El Español referidos (Rudán, 2010: 121).

Sin embargo, podríamos decir, siendo esto una valoración personal, que la gran aportación de Blanco White a la ilustración hispanoamericana no consiste, al menos no exclusivamente, en haber sido vehículo de las ideas de los pensadores ingleses o, en menor medida, de los franceses y alemanes, ${ }^{3}$ ni siquiera en la influencia de los escritos del autor en El Español. En aquellos momentos, Blanco aportó con inmediatez algo que los americanos necesitaban: una defensa y un sustento moral a los movimientos independentistas, elementos capaces de ofrecer cierta cohesión al movimiento emancipador y sus intereses. En las páginas de $E l$ Español se lee, por ejemplo:

Parece que ha llegado la época de un grande acontecimiento político que se ha estado esperando por largo tiempo: el estandarte de la independencia se ha empezado a levantar en América, y según podemos calcular por lo que hemos visto acerca de la revolución de Caracas, no es un movimiento tumultuario y pasajero de aquellos pueblos, sino una determinación tomada con madurez y conocimiento y puesta en

3. Blanco White recibió el aporte intelectual y científico de Alexander von Humboldt, con quien compartía su liberalismo político y económico, su anticlericalismo y culto a la libertad. 
práctica bajo los mejores auspicios: la moderación y la beneficencia. Esto es lo que respiran las proclamas y las providencias del nuevo gobierno de Venezuela (Blanco White, 2009: 59).

La propuesta de Blanco sobre las colonias quedó sintetizada tempranamente ya en los números cuarto y quinto de $E l$ Español (1810), y estaba caracterizada por ser realista y pragmática. White intentó redefinir la relación entre la península y América, asumiendo la obviedad de que algunos americanos querían abandonar la opresión española y los españoles no tenían el despliegue militar suficiente para sujetar los territorios ultramarinos, no solo debido a la gran distancia entre ambas partes del Imperio, sino a la coyuntura que mantenía a España asediada por un poderoso ejército extranjero (Blanco White, 2009). Su postura era, además, conciliadora y, por lo tanto, contraria a la utilización de la fuerza, en la línea de lo que mantuvo a lo largo de su vida (Perdices de Blas y Ramos Gorostiza, 2012: 22):

Blanco urgía a las Cortes a detener la guerra contra América y, previendo (temiendo) lo que estaba por venir, escribió: "Lo más probable es que los americanos sean superiores a las fuerzas europeas; $y$ que después de derramar mucha sangre, el nombre español sea para los nietos de los conquistadores del Nuevo Mundo tan odioso, como el de sus abuelos lo fue a sus primitivos habitantes. La consecuencia de esto sería la separación absoluta de América, y la ruina de la causa de España”.

En otro artículo redactado en julio de 1811 se puede leer:

La América española por necesidad será independiente en algún tiempo (no sabré decir cuando), porque esperar que con sus riquezas, con su extensión, y sus medios ha de estar siempre sujeta a un pueblo que vive a dos mil leguas, aun cuando la gobernara una serie ininterrumpida de Solones, y tuviera al frente de sus fuerzas otros tantos Alexandros, es un verdadero sueño. Pero si los americanos quieren no retardar este 
Blanco White: un militante contra el absolutismo. Del liberalismo a la cuestión colonial

periodo, no lo apresuren, dejen obrar a la naturaleza; la libertad es una planta delicada, que se debilita y perece cuando se la fuerza a dar fruto demasiado temprano (Breña, 2002: 16).

La posición de Blanco iría variando para concluir, una vez decantada la política peninsular por la represión (nombrando a capitanes generales y a virreyes partidarios de la línea dura), en el apoyo a la que considera una inevitable separación e independencia de Hispanoamérica. El 30 de agosto de 1812, Blanco respondía en su periódico a los argumentos esgrimidos por Servando Teresa de Mier en la Segunda carta de un americano al Español:

He hecho cuanto ha estado a mi corto alcance para persuadir a los Americanos a la conciliación; mas, ya no está en su mano ni en la mía. El gobierno español la ha rehusado a la amistad, a la humanidad, a la justicia, y aun a su propio interés. ¿Qué les resta que hacer a los Americanos? 'Se han de entregar a discreción de semejantes señores, fiados en la defensa de una tercera parte de representantes en el Congreso, a esperar justicia de él, contra la que sumariamente le administren sus virreyes y audiencias? Antes me cortara la mano con que escribo que recomendar tan funesto abatimiento. ${ }^{4}$

Mucho después, en 1826, un Blanco ya enfermo y retirado tradujo De la Administración de justicia criminal en Inglaterra; y espíritu del sistema gubernativo inglés, obra de Charles Cottu, que fue publicada en Colombia, Argentina, Chile, Perú y Guatemala. El ilustre traductor escribió también un prólogo a la obra de Cottu donde afirma:

Por lo que hace a los pueblos a quienes esta traducción se dirige, si la benevolencia de un escritor puede redimir sus defectos [...] no hay duda de que la recibirán con favor. Desde el principio de la contienda

4. Puede consultarse en http://www.bicentenario.gob.mx/bdb/bdbpdf/ forasteros/24.pdf

Estado 8 No. 61 
entre España y sus colonias su pluma tomó el partido de la liberalidad y de la justicia; sus paisanos le acusaron de miras siniestras, probablemente porque las pasiones no permitían que otras más nobles miras prevaleciesen en España (Derozier, 1975: 25I).

Y continúa asegurando, con precisión admirable, que:

[h]ablando sin figuras, la América castellana no puede ser otra vez española. No era el poder quien la tenía reunida a España, sino la opinión. Esta se ha desvanecido como las imágenes que el reflejo pinta en la niebla, y no hay fuerza humana que la restablezca (Derozier, 1975: 25I).

Finaliza, en su idea de la política unida a la consciencia de lo irreversible de las luchas por la independencia, sosteniendo:

Concluyan, pues, su obra los hispanoamericanos. Mas reflexionen seriamente que no tienen que esperar reposo hasta que se hayan acostumbrado a sacrificar los intereses individuales al interés general. Hasta que las leyes se miren por los ciudadanos como corazón y principio vital del Estado, y no como gravámenes que cada cual debe procurar eludir por su parte, no esperen felicidad pública. La experiencia les enseñará esta verdad si es que realmente aman a su patria y son dignos de establecer su independencia (Derozier, 1975: 252).

\section{Reflexiones finales}

En Blanco podemos apreciar al pensador y al teórico que ha sabido reflexionar sobre el movimiento ineluctable de la historia. Si hubiésemos de destacar un solo aspecto de la influencia de Blanco White en el constitucionalismo español podríamos decir que su aportación está referida fundamentalmente a la cuestión del control del poder. Su propia biografía evidencia una lucha constante contra el dogmatismo, la intolerancia y cualquier otra expresión de 
Blanco White: un militante contra el absolutismo. Del liberalismo a la cuestión colonial

poder incontrolado y legibus solutus. En el número XXVIII del Semanario, en uno de los artículos más relevantes contra el absolutismo escribe: "el que puede todo lo que quiere, no es posible que sólo quiera lo que debe" (Blanco White 2005: 204; Durán López, 2003), una reformulación edulcorada de la frase contenida en el último número redactado en Madrid y difundido ya en Sevilla, el número XIV: "la costumbre tiene acreditado que el que puede todo lo que quiere, quiere lo que se le antoja" (Blanco White, 2005: 12). En este sentido, Blanco insiste en que el despotismo no era patrimonio privativo de los reyes, sino que en él podían incurrir también las Asambleas, como había sucedido en Francia y como, a su entender, estaba sucediendo en España: "No basta variar las formas de los gobiernos, todos ellos pueden degenerar en despóticos... Las Cortes no están más libres de caer en este despotismo que otra corporación cualquiera" (Blanco White, 2009: 140).

Por otra parte, como ha podido verse, el "pro-independentismo" de Blanco White, criticado hasta la saciedad en su tiempo por sus compatriotas, implicó hacer llegar a Hispanoamérica el pensamiento liberal ilustrado, como si de un pequeño regalo respetuoso se tratara: "estudien las leyes que la obrita siguiente les bosqueja. Estúdienlas no para imitarlas servilmente, sino para beber su espíritu; e imítenlas en cuanto lo permitan su estado presente y sus costumbres" (Derozier, 1975: 252). No nos cabe duda de que la premisa de White en su posicionamiento respecto a la independencia hispanoamericana partía de la premisa de que "sólo lo justo es verdaderamente útil. Si las Américas son provincias de España, iguales deben ser con ella en derechos, sean cuales fueren las consecuencias" (Breña, 2002:14)

En la historia de incomprensión española del problema americano, como dijo Urrutia, Blanco White es un jalón de realismo y de buen sentido. El ejemplo de un discurso 
silenciado por el sistema, pero, sin duda, elaborado también por otros espíritus románticos nacionales. Es el testimonio de una oportunidad perdida, pero también, de una línea de reflexión ocultada. Por esa razón, y por la de haber sido siempre un luchador contra la intolerancia, entre otras, la figura de José María Blanco White es la de un escritor cuya recuperación sigue siendo necesaria.

Consideramos de gran interés un aspecto del trabajo de Blanco que tal vez haya podido intuirse a lo largo de lo escrito en estas páginas, referente al objetivo de su trabajo:

[...] no cabe duda de que su objetivo permanente, más allá de las circunstancias y de sus obsesiones cíclicas, fue siempre la realización de una labor formativa. Su intención fue siempre una intención pedagógica. En efecto, a lo largo de sus años de editor puso todo su empeño en la exposición de ideas y de argumentos que sustentaran su obra reformista (Martínez de Pisón, 2005:16).

Siguiendo al profesor Martínez de Pisón en estas reflexiones finales, es de algún modo esclarecedor mencionar que Blanco White consideraba que la causa principal del abatimiento del país era la obcecación, la falta de pulso vital en el entendimiento, el escaso interés por la reflexión y por la crítica del pensamiento tradicional:

Su misión era, pues, una misión predominantemente educativa. Aunque la actividad de Blanco White se desplegó en el contexto de la revolución española, en ningún modo, era revolucionario. Por el contrario, era un proyecto gradualista, reformista y mesurado que confiaba en los cambios cualitativos y en la formación cultural de los españoles (Martínez de Pisón, 2005: 16).

Resulta difícil estar por completo de acuerdo o en desacuerdo con esta afirmación, pero, en todo caso nos parece importante la cita de Blanco que la acompaña: 
Blanco White: un militante contra el absolutismo. Del liberalismo a la cuestión colonial

No hay país español que no necesite una reforma completa: completa, digo, no violenta, ni inconsiderada. El remedio se debe aplicar de raíz; pero sin arrancarla. Sin alumbrar los entendimientos, afinar el gusto, $y$ elevar el tono general de la opinión pública, en vano se hacen constituciones y se publican leyes.

Fecha de recepción: 10 de diciembre de 2013

Fecha de aceptación: 26 de junio de 2014

Bentham, J., 1988, Política y Derecho en los orígenes del Estado Constitucional, Centro de Estudios Constitucionales, Madrid.

Blanco White, J., I825, Letters from Spain. By Don Leucadio Doblado, Henry Colburn \& Co, Londres.

—. 2005, Obras Completas, Vol. I, Semanario Patriótico, Sevilla, 1809, (edición de Antonio Garnica Silva y Raquel Rico Linage), Almed, Granada.

—_, 2007, Obras Completas, Vol. II, El Español, Números I, 2 y 3. Abril, Mayo, Junio 1810 (edición de Antonio Garnica Silva, José María Portillo Valdés y Jesús Vallejo Fernández de la Reguera), Almed, Granada.

—_, 2009, Obras Completas, Vol. III, El Español, Números 4, 5 y 6. Julio, Agosto y Septiembre de 1810 (edición de Antonio Garnica Silva, José María Portillo Valdés y Jesús Vallejo Fernández de la Reguera), Almed, Granada.

Breña, R., 2002, “José María Blanco White y la Independencia de América: ¿Una Postura Pro-Americana?”, Historia Constitucional, núm. 3, 17 p.

Conway, S. (ed.), 1988, The Collected Works of Jeremy Bentham. The Correspondence of Jeremy Bentham. January 1809-December 1816, Clarendon Press, Oxford.

Derozier, A., 1975, Escritores políticos españoles, I 780-I854, Ediciones Turner, Madrid. 
Bibliografía $\quad$ Dinwiddy, J. R. (ed.), 1988, The Collected Works of Jeremy Bentham. The Correspondence of Jeremy Bentham. January 1802-December 1808, Clarendon Press, Oxford.

—, 1975, "Bentham's Transition to Radicalism", Journal of the History of Ideas, vol. XXXVI, núm. 4, pp. 683-700.

Durán López, F. (ed.), 2003, Crónicas de Cortes del Semanario Patriótico (I8I0-I8I2), Fundación Municipal de Cultura (Biblioteca de las Cortes de Cádiz, 2), Cádiz.

Escamilla Castillo, M. y A. Lázaro Paniagua, 200I, "Blanco White. In Partibus Infidelium”, Anales de la Cátedra Francisco Suárez, Universidad de Granada.

Ferrer Muñoz, M. y J.R. Luna Carrasco, 1996, Presencia de Doctrinas Constitucionales Extranjeras en el Primer Liberalismo Mexicano, UNAM, México.

Llorens, V., 1986, “Introducción a José Blanco White”, en Antonio Garnica (ed.), Cartas de España, Alianza Editorial, Madrid, pp. 8-30.

Martínez de Pisón Cavero, J. M., 2005, "Los Inicios del Pensamiento Liberal Español: José $M^{a}$ Blanco White”, Revista Electrónica del Departamento de Derecho de la Universidad de La Rioja (REDUR), núm. 3, Pp. 7-40.

Méndez Bejarano, M., 2009, Vida y Obras de D. José María Blanco y Crespo (Blanco White), Renacimiento, Sevilla.

Moreno Alonso, M., 1989, "Las ideas constitucionales de Blanco White”, en J. Cano Bueso, Materiales para el Estudio de la Constitución de 18 /2, Parlamento AndaluzTecnos, Sevilla. -, 1997, Blanco White. La obsesión de España, Alfar, Sevilla.

_-, 20II, "Blanco White y la Constitución de 1812 en Inglaterra”, en J. A Escudero (dir.), Cortes y Constitución de Cádiz. 200 años (Tomo III), Espasa, Madrid.

Murphy, M., 1989, Blanco White: Self-banished Spaniard, Yale University Press, New Haven. 
Blanco White: un militante contra el absolutismo. Del liberalismo a la cuestión colonial

Pendás García, B., 199I, "Estudio Preliminar”, en Jeremy Bibliografía Bentham, Tácticas Parlamentarias, Publicaciones del Congreso de los Diputados, Madrid, pp. 27-62.

Perdices de Blas, L. y J. L. Ramos Gorostiza, 20I2, "Blanco White y las Cuestiones Económicas”, Cuadernos de Trabajo de la Asociación Española de Historia Económica, DT-I 204, PP. I-46.

Peset, M. y J. L. Peset, 1974, La Universidad Española (Siglos XVII y XIX). Despotismo Ilustrado y Revolución Liberal, Taurus, Madrid.

Pons, A., 2002, Blanco White y España, Instituto Feijoo de Estudios del Siglo XVIII, Universidad de Oviedo, Oviedo.

Rico Linage, R., 2005, “Introducción”, en Blanco White, Obras Completas, Vol. I, Semanario Patriótico, Sevilla, I809, Almed, Granada, PP. XI-XVIII.

Rodríguez Braun, C., 1985, “'Libraos de Ultramar'. Bentham frente a España y sus Colonias”, Revista de Historia Económica, second series, 3, pp. 497-509.

Rudán, P., 2010, "Más allá de la Querella Benthamista: el Gobierno de Ultramaria", Revista Iberoamericana de Filosofia, Política y Humanidades, núm. 23, pp. I I5-39.

Schwartz, P. y Rodríguez Braun, C. (eds.). 1983, "Cartas españolas de Jeremías Bentham”, Moneda y Crédito, núm. 165, pp. 59-88.

Subirats, E. (ed.), 2005, José María Blanco White: Crítica y Exilio, Anthropos, Barcelona.

Tuñón de Lara, M., 1973, La España del siglo XIX, Laia, Barcelona.

Urrutia Gómez, J., 1991, "El Problema de España y América en Blanco White”, Anuario del Departamento de Filología Española y sus Didácticas, núm. 2, pp. 367-75.

Varela Suanzes, J., 1993, "Un Precursor de la Monarquía Parlamentaria: Blanco-White y El Español (I8I0-|8|4)”, Revista de Estudios Políticos, enero/marzo, núm. 79, pp. I0I-20. 